\title{
A Method for Thermal Analysis of Spiral Bevel Gears
}

Robert F. Handschuh

Vehicle Propulsion Directorate

U.S. Army Research Laboratory

Lewis Research Center

Cleveland, Ohio

and

Thomas P. Kicher

Case Western Reserve University

Cleveland, Ohio

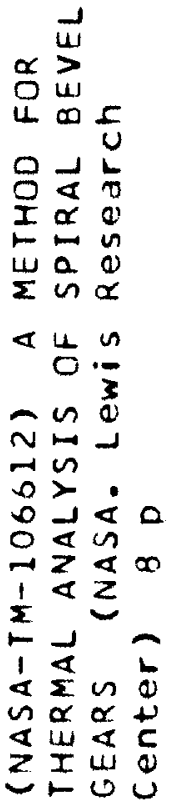

Prepared for the

1994 International Gearing Conference cosponsored by the UK National Gear Metrology Laboratory, University of Newcastle Upon Tyne, and British Gear Association Newcastle Upon Tyne, England, United Kingdom, September 7-9, 1994

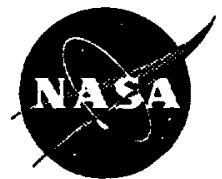

U.S. ARMY

National Aeronautios and

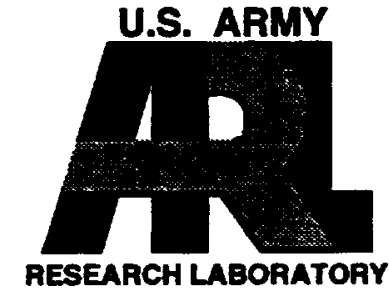


A Method for Thermal Analysis of Spiral Bevel Gears

\author{
Robert F. Handschuh \\ Vehicle Propulsion Directorate \\ U.S. Army Research Laboratory \\ Lewis Research Center \\ Cleveland, Ohio 44135 \\ and \\ Thomas P. Kicher \\ Case Western Reserve University \\ Cleveland, Ohio 44106
}

SYNOPSIS A modelling method for analyzing the three-dimensional thermal behavior of spiral bevel gears has been developed. The model surfaces are generated through application of differential geometry to the manufacturing process for facemilled spiral bevel gears. Contact on the gear surface is found by combining tooth contact analysis with three-dimensional Hertzian theory. The tooth contact analysis provides the principle curvatures and orientations of the two surfaces. This information is then used directly in the Hertzian analysis to find the contact size and maximum pressure. Heat generation during meshing is determined as a function of the applied load, sliding velocity, and coefficient of friction. Each of these factors change as the point of contact changes during meshing. A nonlinear finite element program was used to conduct the heat transfer analysis. This program permitted the time- and position-varying boundary conditions, found in operation, to be applied to a one-tooth model. An example model and analytical results are presented.

\section{INTRODUCTION}

During the design process for spiral bevel gears the most important initial calculations are for the bending and contact stress expected at the design conditions. Typically the process requires many iterations whereby a satisfactory gear configuration emerges. The thermal behavior may be neglected or not even considered if the operational conditions do not warrant its consideration.

In aviation applications, however, the thermal behavior is usually important. These gear meshes can operate at sufficiently high speed and load such that temperatures and scoring can be of concern. A typical aviation spiral bevel design application [1] is shown in the main rotor transmission depicted in Figure (1).

Operational conditions of a given design and the likelihood of a particular failure mode [2,3] are shown in Figure (2). Depending on the operating conditions imposed a region of safe operation can be found for a design. However, if the gear system is loaded sufficiently high or if the operational speed is increased the region of thermal concern can be reached.

The basic understanding of the heat generating mechanism, with respect to gears, began with the early analytical and experimental work of References $[4,5]$. The first thermal analysis of spiral bevel and hypoid gears was contained in the pioneering work of Reference [6]. The procedures of References $[6,7]$ are still in use today and are very useful in evaluating several design candidates in a quick manner.

The finite element analysis technique has the capability to model extremely complex structures and boundary conditions and has gained popularity in recent years. The first finite-element-based thermal study of spiral bevel gears was developed by Reference [8]. An influence coefficient methodology was used to determine tooth stiffness and bulk temperature. The resulting formulation was used to predict dynamic load and gear temperature. The results found were consistent with those of References $[6,7]$.

The modelling procedure to be described herein is based on combining gear design/gear geometry, 3-D Hertzian contact theory, and operating conditions with a finite element analysis procedure [9]. Therefore the objective of this report is to describe the procedure necessary to build the model, configure the boundary conditions, and conduct the analysis to assess the thermal behavior of spiral bevel gears.

\section{SPIRAL BEVEL GEAR SURFACE DETERMINA- TION}

The spiral bevel gear manufacturing process that will be briefly described in this section is that of the face-milled type. The main components used in this type of manufacture, shown in Figure (3), are the head cutter, the cradle, and the workpiece.

The head cutter contains either cutting blades or a grinding wheel that have a conical shape. The conical shape describes the so-called blade angle. The rotational speed of the head cutter is controlled to produce the most efficient metal removal and is not related to the produced gear geometry.

The head cutter is mounted on the cradle, at a distance from the cradle center and orbits this center during 
manufacture. Location of the cutter axis with respect to the cradle axis depends on the cutter diameter used and on the required mean spiral angle of the workpiece.

The cradle and workpiece are rotated in a predetermined relationship called the ratio of roll. In older machine tools this motion was produced through index gears, cams, and shafts that mechanically linked the cradle and workpiece. Machines produced today use computer numerical controlled motion that duplicates the generation motion of the older machine tools.

The numerical simulation of the manufacturing process uses the procedure developed in References [10-13]. In these references the gear tooth surfaces are described using a differential geometry approach. Homogeneous coordinates are used and permit the coordinate transformations to be performed for rotations and translations simultaneously. An "Equation of Meshing" is used to relate the machine settings and cutter geometry to the surface being generated. This equation numerically states that the normal vector of the generating surface must be perpendicular to the relative velocity between cutter and the gear tooth surface at the point in question (the scalar product between these vectors is zero).

Taking the procedure one step further permits the description of the surface coordinates of the gear under study [14]. Using the design data of the gear along with the equation of meshing permits the calculation of tooth surface locations of interest. The objective of this process is to find the unknown parameters of the cutter and orientation of the cutter that satisfy the equation of meshing for radial and axial locations on the gear profile.

To develop the finite element model, needed for the analysis, the procedure described above is repeated for a grid of locations on the concave and convex sides of the tooth surface. The present analysis uses a grid of 10 by 10 points as shown in Figure (4).

From the rest of the gear design information a threedimensional model can be generated with a geometric modelling package [15]. Now the model needs to have the finite element mesh and the boundary conditions applied.

\section{TOOTH CONTACT ANALYSIS, THREE- DIMENSIONAL CONTACT ANALYSIS, AND HEAT GENERATION}

Spiral bevel gears are manufactured with an intentional mismatch between surfaces. This is done so that the gear mesh can perform in a satisfactory manner even when misalignment, manufacturing errors, or high load cause the gears to deflect to locations different than what was called for in their design. While conjugate motion would provide the ideal transmission of motion, this is not practical in spiral bevel gears.

Therefore spiral bevel gears operate with a certain amount of transmission error, defined as the deviation from the intended gear ratio, to maintain the ability to perform successfully over a range of conditions. The basis of tooth contact analysis is described in Reference [16]. Many others since Reference [16] also have investigated the kinematics of spiral bevel gears $[11-13,17,18]$.
In the study described herein, the curvatures of the meshing surfaces as the contact moves across the gear tooth surface, the velocities of the meshing surfaces, and the load based on one tooth pair carrying the entire load are also important. This information was determined using the computer program of Reference [19].

Therefore at this point the transmission error as a function of mesh position is known and is shown in Figure (5) for the example data of Table 1. The data of Table 1 is for the test specimen of the NASA Spiral Bevel Gear Rig [20]. The no-load transmission error curve is shown for three adjacent teeth in this figure. Where the curves overlap, two pairs of teeth will be assumed to be in contact; otherwise only one pair will carry the entire load. The parabolic shape of the error curve (see Figure (5)) tends to absorb the transmission errors caused by misalignment and other defects [21].

From the analysis of Reference [19], the velocities of the meshing members are known with respect to a plane perpendicular to the common normal at the point of contact. The curvatures of the surfaces at the point of contact under the load will produce an elliptical hertzian contact. The velocities of the meshing gears are described in this plane with respect to the major-minor directions of the contact ellipse. These parameters will be used to find the hertzian contact and heat generated as a function of mesh position.

The contact between the surfaces must be determined next. Using the results of Reference [19] and the load sharing assumed, as shown in Figure (5), three-dimensional contact analysis is conducted $[22,23]$. The curvatures found at the points of contact from the no-load tooth contact analysis are assumed to exist over both contacting bodies. Therefore at each point of contact the ellipse size and maximum contact pressure are found based on the principal curvatures, their orientation, load, and material properties of the gears.

Finally the heat generation as a function of mesh position must be found. Only the heat generated due to surface relative sliding was considered. The heat generated due to sliding is the product of the coefficient of friction, load, and sliding velocity. At this point only the friction coefficient still needs to be determined.

Friction characteristics of several lubricants, over a range of operating conditions and gear surface finishing has been reported in References [24,25]. The data of Reference [25], for a turbine engine oil such as that used in aerospace power transmission, will be utilized in this report. A typical set of results for friction as a function of sliding-to-rolling velocity ratio and three different rolling velocities is shown in Figure (6).

Therefore the combination of the assumed load sharing, the calculated velocities, coefficient of friction and heat generation are plotted in Figures (7) and (8) for fifteen contact locations, $2.5^{\circ}$ of pinion rotation apart, as the gear tooth pair goes through mesh. This rotation amount represents the entire meshing cycle of a single tooth pair. 


\section{FINITE ELEMENT MODEL, BOUNDARY CONDI- TIONS, AND EXAMPLE ANALYSIS}

A finite element model was created as described above for a one tooth sector of the spiral bevel pinion (for basic design data see Table 1). Eight-node isoparametric heat transfer elements were used. A total of 20,250 elements and 22,586 grid points were contained in the model. The resultant model is shown in Figure (9). A total of 874 grid points were located on the drive-side profile (concave side). These points could be exposed to the time- and positionvarying heat flux that gear meshing causes.

Locations on the active profile where the contact ellipse, based on the three-dimensional contact analysis conducted, overlapped the finite element grid needed to be found. The active profile grid points were put into a radial-axial plane. Next the ellipse size and orientation were projected onto a similar plane. Then the intersection of active profile grid points contained within the ellipse were found. The result of ellipse $\# 10$ of the 15 used in this example for the analysis conducted herein is shown in Figure (10). Shown are the major-minor ellipse dimensions and the resultant grid points contained within the ellipse. This procedure is repeated for each ellipse. In this manner the time-varying flux locations are determined.

Next the heat flux was distributed to the grid points contained within a particular ellipse. In the present analysis the heat flux was distributed based on the distance from the center of the contact. A fairly flat elliptical shape was chosen and the heat flux was then distributed.

Heat transfer coefficients for the model were determined using applicable data for some classic geometries from heat transfer texts. A listing of the heat transfer coefficients for the various surfaces of the finite element model is given in Table 2.

The implementation of the boundary conditions was controlled using subroutines appended to the bulk data of the finite element model [26]. The analysis uses two sets of subroutines. First, the time-averaged heat flux, which is the heat flux totaled at each active profile grid point, averaged over an entire revolution, is used. This is done to reduce the computation time necessary for the solution to reach a predetermined elapsed time. Then the subroutine is substituted with the time- and position-varying boundary conditions.

The example temperature field results are shown in Figures (11) and (12). In Figure (11) a single grid point on the active profile is followed for several revolutions after the subroutines were switched from the time-averaged to the time- and position-varying boundary conditions. The grid point temperature fluctuates between the coolest just before entering mesh to the highest as the contact ellipse moves over the grid point. For the grid point chosen a temperature fluctuation of $35^{\circ} \mathrm{C}$ is predicted.

Another way to look at the results is through looking at the three-dimensional temperature field on the model at various times during the solution. An example of the temperature field at the $13^{\text {th }}$ of 15 contact ellipses is shown in Figure (12). The temperature field of the model ranges from $75^{\circ} \mathrm{C}$ far away from the contact to approximately $200^{\circ} \mathrm{C}$ on the drive-side profile where contact occurs.

\section{CONCLUSIONS}

A method for the determination of the thermal behavior of spiral bevel gears has been presented. The method can be used to determine the steady state behavior as well as the time- and position-varying temperature field. The finite element method was used to model and analyze the thermal behavior. A one tooth sector model of a spiral bevel pinion was used as an example of the technique. The results of the example analysis demonstrated that locations on the active profile can experience temperature "flashes" of over $40^{\circ} \mathrm{C}$. Locations not on the active profile tended to be unaffected by the moving heat flux.

\section{REFERENCES}

[1] Lewicki, D. and Coy, J.:"Vibration Characteristics of OH-58A Helicopter Main Rotor Transmission", NASA TP2705, AVSCOM TR 86-C-42, April, 1987.

[2] Borsoff, V.:"Predicting the Scoring of Gears", Machine Design, Vol. 37, Jan., 1965.

[3] Townsend, D.: "Lubrication Considerations in Gear Design", NASA TMX-52942, Dec. 1970.

[4] Blok, H.: "Theoretical Study of Temperature Rise at Surface of Actual Contact Under Oiliness Lubricating Conditions", I. Mech. E., London, Proc. Gen. Disc. Lubrication, Vol 2, 1937.

[5] Blok, H.:"Measurement of Temperature Flashes on Gear Teeth Under Extreme Pressure Conditions", I.Mech.E., London, Proc. Vol 1-2, 1937.

[6] Coleman, W.:"A Scoring Formula for Bevel and Hypoid Gear Teeth", J of Lubrication Technology, Trans. of the ASME, April, 1967.

[7] "Scoring Resistance of Bevel Gear Teeth", The Gleason Works, Rochester, New York, 1966.

[8] Chao, H., and Cheng, H.: "A Computer Solution for the Dynamic Load, Lubricant Film Thickness, and Surface Temperatures in Spiral Bevel Gears", NASA CR-4077, July, 1987.

[9] Handschuh, R.: "Thermal Behavior of Spiral Bevel Gears", PhD Dissertation, Case Western Reserve University, August, 1993.

[10] Litvin, F.:Theory of Gearing, NASA RP-1212, AVSCOM TR-88-C-035, Dec. 1989.

[11] Litvin, F. and Lee, H.:"Generation and Tooth Contact Analysis of Spiral Bevel Gears With Predesigned Parabolic Functions of Transmission Errors", NASA CR4259, AVSCOM TR 89-C-014, 1989. 
[12] Litvin, F. and Zhang, Y.:"Local Synthesis and Tooth Contact Analysis of Face-Milled Spiral Bevel Gears", NASA CR-4342, AVSCOM TR-90-C-028, 1991.

[13] Litvin, F., Zhang, Y., and Handschuh, R.: "Local Synthesis and Tooth Contact Analysis of Face-Milled Spiral Bevel Gears", NASA TM-105182, AVSCOM TR 91-C039, Sept. 1991.

[14] Handschuh, R. and Litvin, F.:"A Method for Determining Spiral Bevel Gear Tooth Geometry for Finite Element Analysis", NASA TP-3096, AVSCOM TR-91-C020, Aug., 1991.

[15] PDA Engineering, PATRAN Plus, Release 2.5, Costa Mesa, CA, 1991.

[16] "Understanding Tooth Contact Analysis", The Gleason Works, Rochester, New York, 1981.

[17] Gosselin, C., Cloutier, L., and Brousscue, J.: "Tooth Contact Analysis of High Conformity Spiral Bevel Gears", JSME Int. Conf. on Motion and Power Transmission, Hiroshima, Japan, Nov. 1991.

[18] Gosselin, C., Cloutier, L., and Nguyen, Q.: "The Influence of the Kinematical Motion Error of Spiral Bevel Gears", AGMA Fall Technical Meeting, 1992.

[19] Litvin, F., Zhang, Y., and Chen, J.: "User's Manual for Tooth Contact Analysis of Face-Milled Spiral Bevel Gears With Given Machine-Tool Settings", NASA CR189093, AVSCOM TR 91-C-051, Dec., 1991.

[20] Handschuh, R.: "Effect of Lubricant Jet Location on Spiral Bevel Gear Operating Temperatures", NASA TM105656, AVSCOM TR 91-C-033, Sept., 1992.

[21] Litvin, F., Chen, N., Hsiao, C., and Handschuh, R.: "Generation of Helical Gears With New Surfaces, Topology by Application of CNC Machines", NASA TM106175, ARL-TR-9, June, 1993.

[22] Timoshenko, S., and Goodier, J.:Theory of Elasticity, McGraw-Hill, 1951.

[23] Boresi, A., Sidebottom, O., Seely, F., and Smith, J.:Advanced Mechanics of Materials, John Wiley \& Sons, 1978.

[24] Ku, P., Staph, H., and Carper, H.: "Gear Tooth Scoring Investigation", Southwest Research Institute, USAAMRDL-TR-75-33, July, 1975.

[25] Tevaarwerk, J.: "Constitutive Modeling of Lubricants in Concentrated Contacts at High Slide to Roll Ratios", NASA CR-175029, Dec. 1985.

[26] MARC Finite Element Program, Revision K4-1, Marc Analysis Research Corporation, Palo Alto, CA,
1990.

\begin{tabular}{|c|c|}
\hline 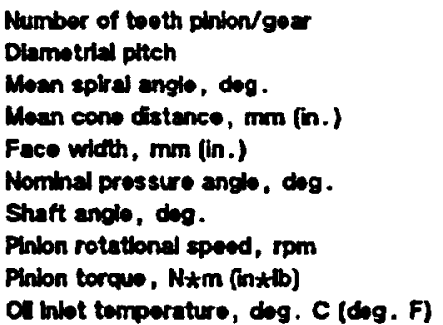 & $\begin{array}{c}12 / 36 \\
5.141 \\
35 \\
81.1(3.191) \\
25.4(1.0) \\
22.5 \\
90 \\
14400 \\
356(3150) \\
38(100)\end{array}$ \\
\hline
\end{tabular}

Table 1 - Gear design and operating conditions for the example analysis.

\begin{tabular}{|l|c|}
\hline \multicolumn{1}{|c|}{ Surface } & $n\left(W /\left(m^{2} \star^{\circ} \mathrm{c}\right)\right)$ \\
\hline Ditve slde of tooth & 4450 \\
Coest stde of tooth & 50 \\
Tooth top tand & 50 \\
Tooth too & 180 \\
Tooth hoel & 160 \\
Axial sections of gear & 0 \\
Gear body inside dameter & 0 \\
\hline
\end{tabular}

Table 2 - Heat transfer coefficients used for the example analysis.

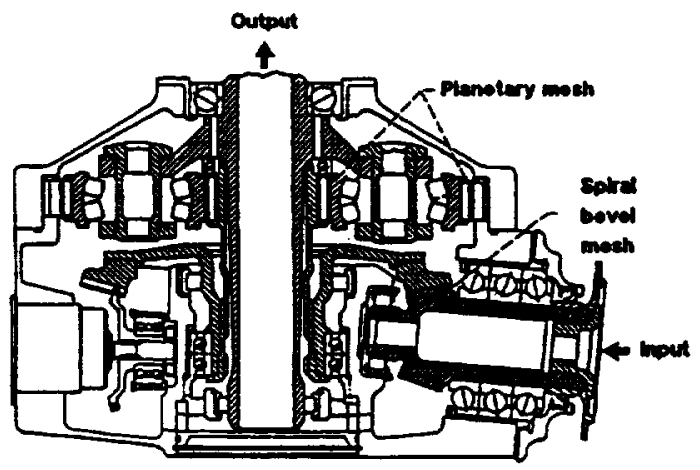

Figure 1 - OH-58A helicopter main rotor transmission.

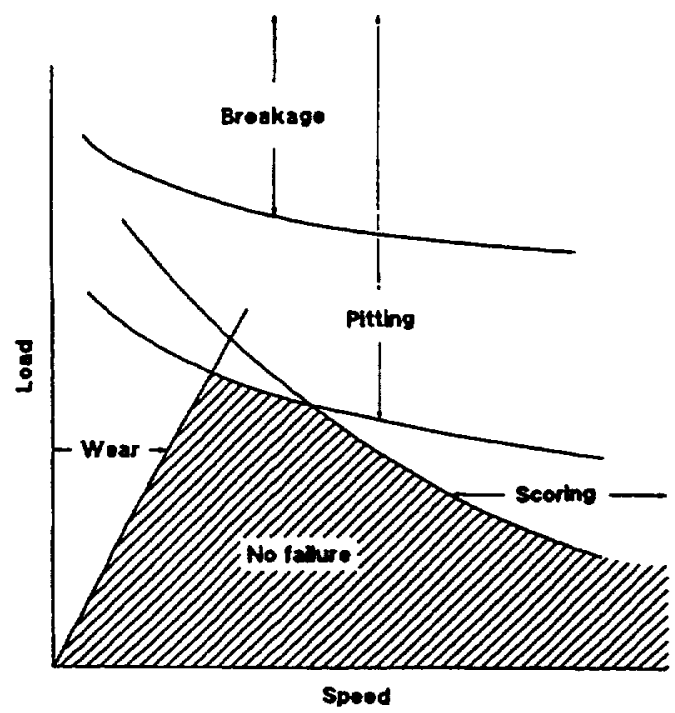

Figure 2 - Gear design parameters of concern based on operating conditions. 


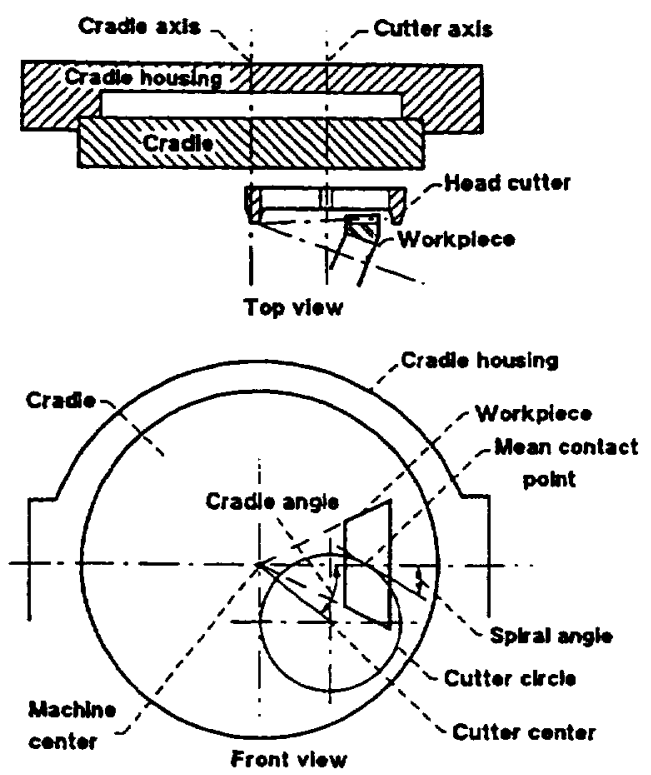

Figure 3 - Orientation of workpiece to generation machinery.

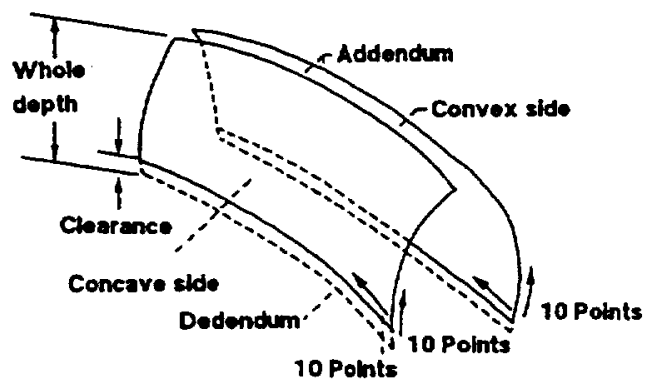

Figure 4 - Calculation points ( 10 by 10 grids, i.e., 100 points each side) for concave and convex sides of tooth surface.

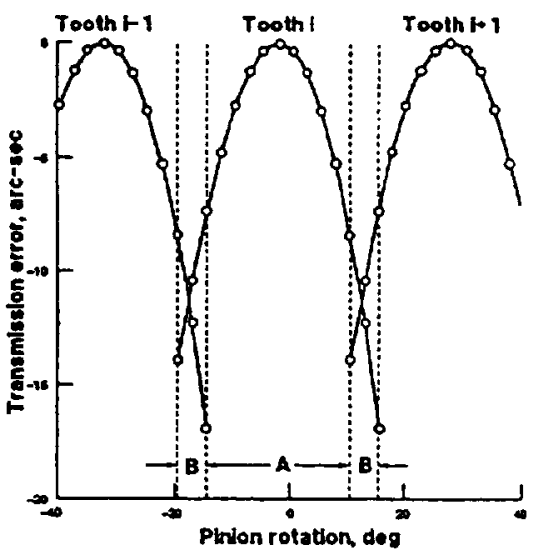

Figure 5 - Transmission error of output gear rotation as a function of pinion rotation angle (region $A-1$ tooth pair in contact; B - 2 pairs in contact).

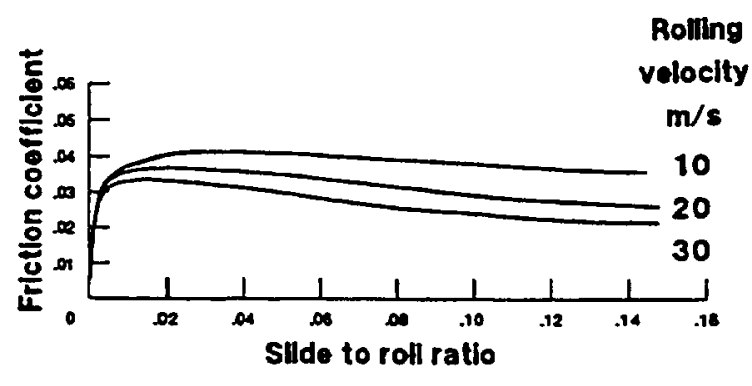

Figure 6 - Typical friction data as taken from Ref.[24] for a turbine engine lubricant at $37^{\circ} \mathrm{C}$ and a maximum contact pressure of $1.92 \mathrm{GPa}$.

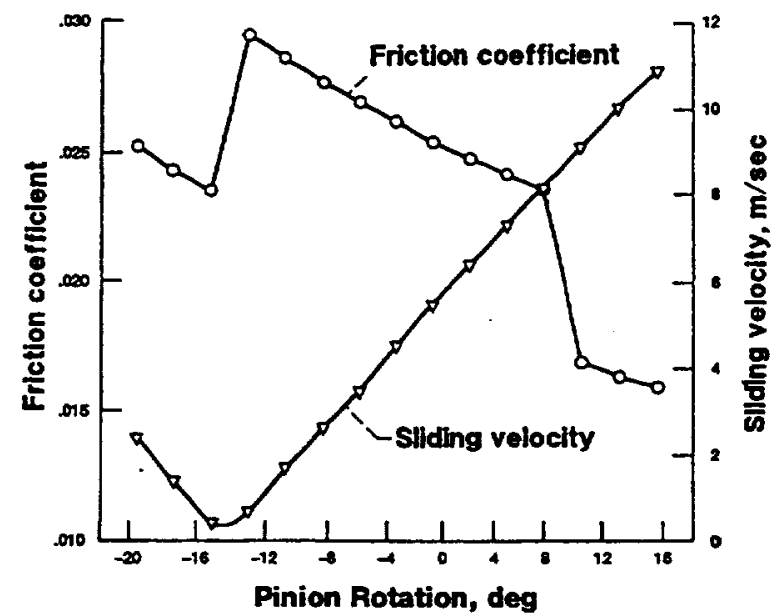

Figure 7 - Friction coefficient and sliding velocity as a function of pinion rotation angle.

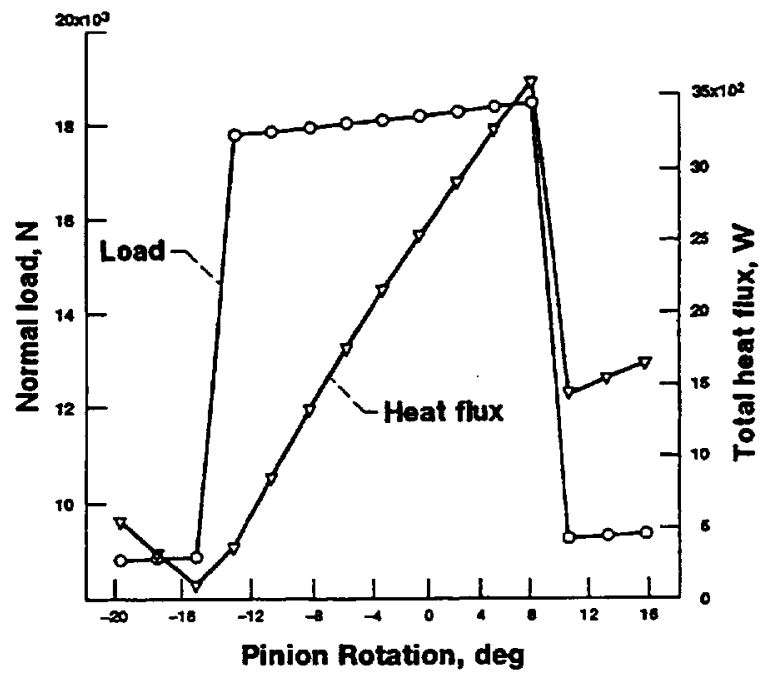

Figure 8 - Load and heat flux as a function of pinion rotation angle. 


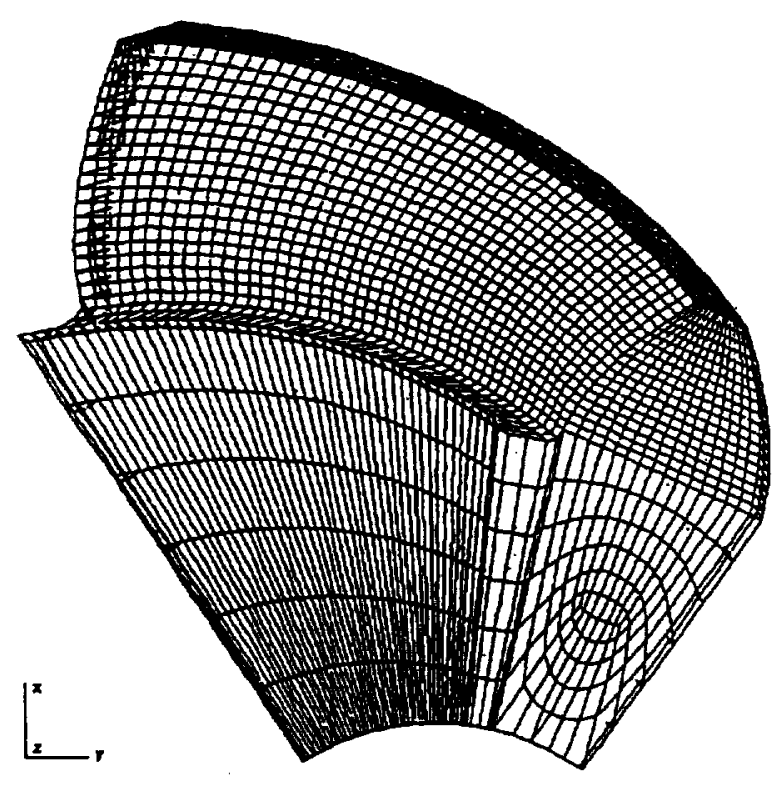

Figure 9 - Finite element model used for heat transfer study.

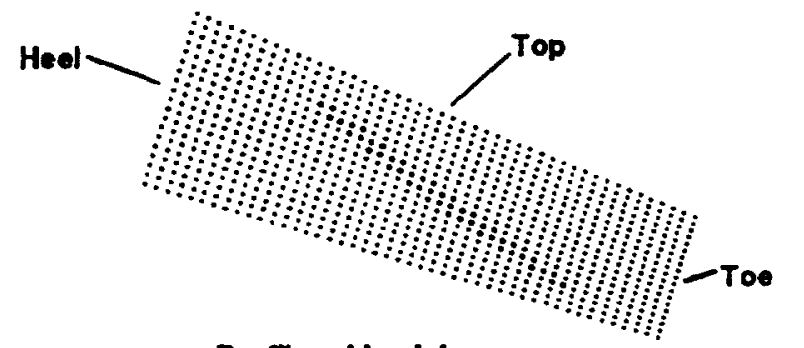

- - Proflle grid point

- - Profile grid point with

heat flux applied

Figure 10 - Contact ellipse number 9 of 15, shown plotted on the entire concave profile grid.

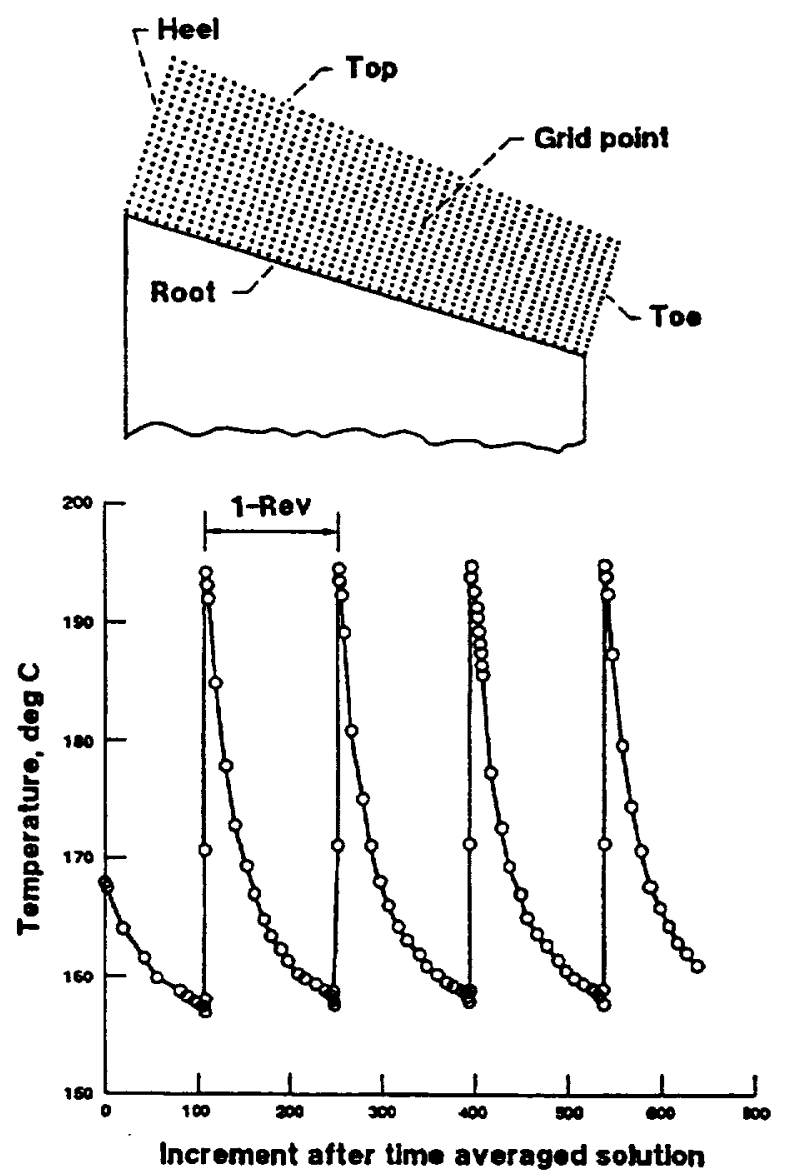

Figure 11 - Active profile grid point location and temperature transient.

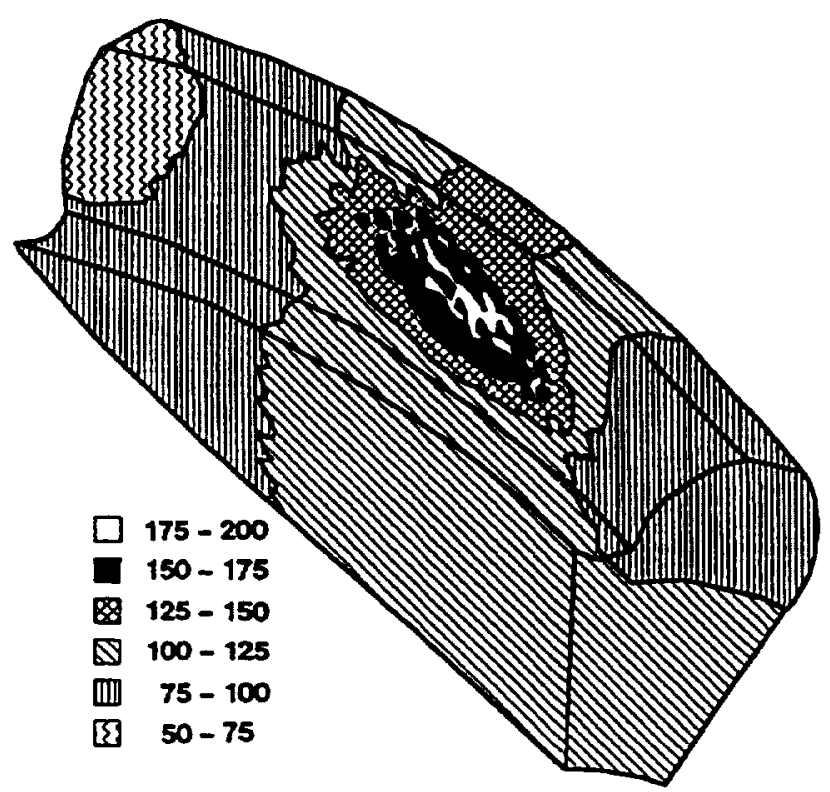

Figure 12 - Temperature field for increment number thirteen heat flux using finite element model $\left({ }^{\circ} \mathrm{C}\right)$. 
Public reporting burden for this collection of infomation is estimaled to average 1 hour per response, including the time for reviewing lnstructions, seanching existing data sources, gathering and maintaining the data needed, and completing and reviewing the collection of information. Send comments regarding this burden estimate or any other aspect of this collection of information, including suggastions for reducing this burden. to Washington Headquarters Services, Directorate lor Information Operations and Reports, 1215 Jefl

\begin{tabular}{|l|l|l}
\hline 1. AGENCY USE ONLY (Leave blank) & $\begin{array}{c}\text { 2. REPOAT DATE } \\
\text { July } 1994\end{array}$ & $\begin{array}{r}\text { 3. AEPORT TYPE AND DATES COVERED } \\
\text { Technical Memorandum }\end{array}$ \\
\hline
\end{tabular}

4. TITLE AND SUBTITLE

A Method for Thermal Analysis of Spiral Bevel Gears

6. AUTHOR(S)

Robert F. Handschuh and Thomas P. Kicher

7. PERFORMING ORGANRATION NAME(S) AND ADORESS(ES)

NASA Lewis Research Center

Cleveland, Ohio 44135-3191

and

Vehicle Propulsion Directorate

U.S. Army Research Laboratory

Cleveland, Ohio 44135-3191

9. SPONSORINGMONITORING AGENCY MAME(S) AND ADDRESS(ES)

National Aeronautics and Space Administration

Washington, D.C. 20546-0001

and

U.S. Army Research Laboratory

Adelphi, Maryland 20783-1 145
5. FUNDING NUMBERS

WU-505-62-36

1L161102AH45

8. Performing organization

REPORT NUMBER

E-8895

10. SPONSORINGMONITORING AGENCY REPORT NUMBER

NASA TM-106612

ARL-TR-457

11. SUPPLEMENTARY NOTES

Prepared for the 1994 International Gearing Conference, cosponsored by the UK National Gear Metrology Laboratory, University of Newcastle Upon Tyne, and British Gear Association, Newcastle Upon Tyne, England, United Kingdom, September 7-9, 1994. R.F. Handschuh, Vehicle Propulsion Directorate, U.S. Army Research Laboratory, NASA Lewis Research Center, and T.P. Kicher, Case Western Reserve University, Cleveland, Ohio 44106. Responsible person, R. Handschuh, organization code 2730, (216) 433-3969.

128. DISTRIBUTION/AVAILABILITY STATEMENT 12b. DISTRIBUTION CODE

Unclassified - Unlimited

Subject Category 37

13. ABSTRACT (Maximum 200 words)

A modelling method for analyzing the three-dimensional thermal behavior of spiral bevel gears has been developed. The model surfaces are generated through application of differential geometry to the manufacturing process for face-milled spiral bevel gears. Contact on the gear surface is found by combining tooth contact analysis with three-dimensional Hertzian theory. The tooth contact analysis provides the principle curvatures and orientations of the two surfaces. This information is then used directly in the Hertzian analysis to find the contact size and maximum pressure. Heat generation during meshing is determined as a function of the applied load, sliding velocity, and coefficient of friction. Each of these factors change as the point of contact changes during meshing. A nonlinear finite element program was used to conduct the heat transfer analysis. This program permitted the time- and position-varying boundary conditions, found in operation, to be applied to a one-tooth model. An example model and analytical results are presented.

14. SUBJECT TERMS

Gears; Heat transfer; Finite elements

15. NUMBER OF PAGES 8

16. PRICE CODE

$\mathrm{A} 02$

17. SECURITY CLASSIFICATION OF REPORT

Unclassified
18. SECURITY CLASSIFICATION OF THIS PAGE

Unclassified
19. SECUAITY CLASSIFICATION OF ABSTRACT Unclassified 